\title{
Fracciones y relaciones intrapartidarias en el último gobierno neobatllista (1954-1956)
}

\author{
Factions and intra-party relations \\ in the last neobatllista government (1954-1956)
}

\section{Camilo López Burian*}

\footnotetext{
* Profesor adjunto en el Departamento de Ciencia Política, Facultad de Ciencias Sociales, Universidad de la República (Uruguay). Doctor en Ciencia Política por la misma institución. Investigador activo nivel I del Sistema Nacional de Investigadores de la Agencia Nacional de Investigación e Innovación.

凹·camilo.lopez@cienciassociales. edu.uy http://orcid.org/0000-00031185-854X
}

RECIBIDO: 27.9.2019

ACEPTADO: 1.11 .2019

\begin{abstract}
Resumen
En 1954 el Partido Colorado ganó las elecciones para la conformación del Poder Ejecutivo colegiado y parlamentarias, con mayorías en el Parlamento. Sin embargo, Luis Batlle Berres -líder de la Lista 15, una de las fracciones coloradas batllistas- asumió la presidencia del Poder Ejecutivo colegiado en 1955, luego de una dura negociación intrapartidaria para garantizar el apoyo en el Parlamento a la mayoría de su partido. A partir de un análisis de la formación de este gobierno, se dialoga con la literatura que ha caracterizado las relaciones intra- e interpartidarias en el proceso, a la vez que se reconstruye un momento histórico clave para comprender la crisis del Uruguay batllista, dado que luego de este período de gobierno, en 1958, el Partido Colorado sería derrotado electoralmente por el Partido Nacional.
\end{abstract}

Palabras clave: Uruguay, historia política, partido político.

\footnotetext{
Abstract

In 1954, the Colorado Party won the elections for the conformation of the Collegiate Executive Branch and parliamentary elections, thus obtaining a majority in Parliament. Luis Batlle Berres took over the presidency in 1955 after a difficult intraparty negotiation to attain
} 
parliamentary support. He was Head of the List 15, a faction of the Colorado Party from a political sector known as Batllistas. Since the Colorado Party would lose the following election in 1958 to the National Party, this paper analyses the formation of this last neobatllista government, in dialogue with the literature that has characterized inter and intraparty relations, so as to reconstruct a key historical moment and understand the crisis of the so called Uruguay Batllista.

Keywords: Uruguay, political history, political parties.

\section{Introducción 1}

El batllismo retornó al gobierno tras la victoria electoral de Tomás Berreta, en 1946. Su vicepresidente, Luis Batlle Berres asumió la Presidencia luego de la muerte de Berreta, en agosto de 1947. Se iniciaba el período neobatllista, ${ }^{2}$ que se extendería hasta la derrota colorada en las elecciones de 1958. En el contexto del mundo bipolar de la Guerra Fría, Uruguay transitó de la prosperidad a la crisis. ${ }^{3}$ Y el gobierno iniciado en 1955 es un mojón clave en este derrotero. Analizar su formación, que muestra también la debilidad política que lo llevaría a la crisis, es el objetivo de este trabajo.

Sobre la dinámica política que caracterizó a este período, Gerardo Caetano y José Rilla $(1995,2000)$ señalan una forma intermedia entre el gobierno de partido y la coalición, donde los partidos políticos son caracterizados más como sujetos de cogobierno que de gobierno, a partir de advertir una fuerte matriz de acuerdo interpartidario. En contraposición, Jorge Lanzaro sostiene que estas prácticas son muestras de compromiso y caracteriza la dinámica política del período señalando:

Agradezco a quienes anónimamente revisaron este trabajo por su generosa ayuda para mejorarlo. Agradezco a Daniel Chasquetti, en cuyo curso de la Maestría en Ciencia Política inicié hace mucho tiempo esta investigación y recibí sus orientaciones. Los errores son responsabilidad exclusivamente mía.

2 El término neobatllismo fue elaborado por Germán D’Elía (1982). En el capítulo tercero de esa obra puede verse un análisis de su propuesta política, o ideología, como la denomina el autor, y es de particular interés el diálogo que entabla entre el neobatllismo y experiencias populistas latinoamericanas contemporáneas. Como señala Pablo Ferreira: «Caetano y Rilla (1996:178), si bien utilizan el término, sostienen que "el cuadro restaurador parecía darse en toda la línea, al punto tal que hasta podría discutirse la denominación de este período como de neobatllista, por todo lo que el prefijo exige de novedad, de redefinición, de proyección genuina de un legado". En un trabajo publicado por los mismos autores años después (Caetano y Rilla, 2003: 36) ya no utilizan el término haciendo referencia al "impulso restaurador" del segundo batllismo» (2013a, p. 20).

3 Este texto no analiza esta crisis en profundidad. Para tener una mirada más abarcadora y que recoge las diferentes visiones sobre la crisis que surgieron de forma contemporánea al proceso, se sugiere ver el trabajo de Espeche (2016). 
[...] tendremos mandatos que pueden asimilarse a los gobiernos de minoría, puesto que son encabezados por la fracción más votada del partido ganador, que por sí sola no tiene mayoría en el parlamento. La acumulación electoral aporta el caudal de sufragios y los elementos de legitimidad para la investidura presidencial, pero no se convierte necesaria e inmediatamente en coalición de gobierno. Por el contrario [...] la competencia interna que se ventila en las elecciones a través del doble voto simultáneo, se proyecta sobre las incidencias del período intercomicial. (2000, p. 100)

Por su parte, Martín Sacchi (1999), al abordar los gobiernos de 1955 a 1967, concluye que estos se sustentaron principalmente en relaciones intrapartidarias de cooperación, a partir de la bancada de la fracción mayoritaria como núcleo del gobierno y una primera base de apoyo constituida por el resto de su partido, pero no constata acuerdos entre fracciones de diferentes partidos. Y en términos generales Romeo Pérez (1988) señala que nuestra segunda poliarquía (1942-1973) (Chasquetti y Buquet, 2004) se caracterizó por la «complejización del consenso».

A la luz de estos análisis y, como se verá más adelante, en diálogo con la producción que desde la historia se ha realizado sobre el período, este trabajo observará las características de la dinámica política - en términos de competencia y cooperación-a partir de los incentivos y constreñimientos que las instituciones generan en los actores. Por ello, primero se abordan las características del régimen de gobierno, del sistema electoral y el sistema de partidos, para luego atender a la dinámica de los actores, haciendo foco en la campaña electoral, las elecciones y, principalmente, en la formación del gobierno. Al iniciar el trabajo de reconstrucción histórica se esperaba encontrar un proceso políticamente conflictivo, ya que, recordando el proceso de formación del gobierno, Luis Batlle Berres manifestó desde Radio Ariel: «Fuimos obligados a mendigar el acuerdo de los colorados para gobernar». A explorar este momento se dedican las siguientes páginas.

\section{El presidencialismo de la Constitución de 1952}

Los integrantes de la coalición reformista que gestó la Constitución de 1952 perseguían tres objetivos disímiles pero no contradictorios: unos estaban convencidos de que implantar un Ejecutivo colegiado puro era un cambio en sí mismo positivo; otros buscaban aumentar las oportunidades del partido mayoritario menor para participar y controlar la gestión gubernativa, mientras otros solo procuraban bloquear otra presidencia de Luis Batlle Berres. 
Como muestra D’Elía (1982, pp. 61-65), existía en el país una inquietud relacionada con la situación económica y financiera, en un contexto de crisis social en avance, mientras la Guerra Fría vivía un episodio caliente en Corea (1950-1953). Esta situación, señala D’Elía (1982, p. 62), se tradujo en la búsqueda de fortalecer al gobierno mediante una reforma constitucional. El herrerismo tuvo un relevante papel en su aprobación, con el incentivo de integrar, al menos minoritariamente, el Ejecutivo y la dirección de entes comerciales e industriales del Estado (1982, p. 62). Como señala Ferreira:

La coyuntura de 1951 invertía la ecuación política de julio de $1916 .{ }^{4}$ En aquel entonces se habían encontrado alineados el reformismo económico y social con la propuesta de reforma política. [...] La nueva coyuntura invertía algunos roles. Una fuerte alianza entre el centro liberal del espectro político y algunos sectores ubicados claramente en la derecha política acordaba e impulsaba la reforma constitucional. La nueva constitución era planteada de forma explícita como un pacto del sistema de partidos destinado a enfrentar la movilización creciente de la sociedad civil y de manera implícita era concebida como una estrategia de bloqueo al sector más progresista del propio sistema. (2013a, p. 7).

Para el sector liderado por Batlle Berres, a quien buscaban bloquear, oponerse a la reforma tenía costos. Los cambios incluían el colegiado integral, propuesta histórica del batllismo que estaba incluida en su programa partidario. El presidente Andrés Martínez Trueba e importantes dirigentes quincistas la impulsaban. Así el entorno de Batlle Berres se concentró en denunciar móviles poco democráticos de cualquier apoyo herrerista a la reforma y en exigir la realización de una Asamblea Nacional Constituyente para incluir en el proyecto elementos relacionados con los avances económicos y sociales 5 (Ferreira, 2013a, p. 8).

Los comicios de 1950 mostraron, en la interna del Partido Colorado (PC), al batllismo dividido en dos fracciones: la Lista 15, encabezada por Luis Batlle Berres, sobrino de José Batlle y Ordóñez, y la Lista 14, encabezada por César y Lorenzo Batlle Pacheco, hijos de José Batlle y Ordóñez, que mantenían desde hacía ya varios años una relación conflictiva con el líder de la 15. Los Batlle Pacheco impulsaban el colegiado utilizando en el discurso los argumentos otrora usados por su padre. Mientras tanto, en tiendas de la Lista 15 el interés por esta reforma era moderado, y el discurso, como se señaló, evaluaba que la coyuntura económico-social del país demandaba atención por sobre otras dimensiones de la realidad nacional.

$4 \quad$ Sobre este proceso véase, por ejemplo, Barrán y Nahum (1987).

5 La referencia a este posicionamiento se hace a partir de «El discurso de Luis Batlle en Paysandú. Expuso claramente su pensar sobre la Reforma Constitucional» (Acción, 15 de agosto, 1951, p. 1). Se toma este análisis de Ferreira (2013a). 
El Partido Nacional (PN), bajo la hegemonía de Luis Alberto de Herrera, criticaba el formato institucional nacido en 1942 - que le quitaba el nivel de coparticipación que había tenido durante el período terrista - como falto de legitimidad y eficacia. El Partido Nacional Independiente (PNI) se mostraba afín a la reforma, e incluso había apoyado a los batllistas en la reforma constitucional de 1942. Solamente el Partido Socialista y el Partido Comunista no se mostraban a favor de la reforma.

Con este escenario, en 1951 el nuevo presidente, Andrés Martínez Trueba, comenzó a contactarse con la dirigencia del PN a fin de encaminar el proceso de reforma. Para su elaboración se creó una comisión extraparlamentaria que formuló un texto consensuado, el cual fue aprobado por las autoridades del PC y el PN el 31 de julio de 1951. Luego se presentó en el Parlamento. La ley constitucional fue sancionada con los dos tercios de cada Cámara a fines de octubre de 1951, ratificada en un plebiscito el 16 de diciembre del mismo año y comenzó a regir el 25 de enero de 1952.

Como señala Daniel Chasquetti (2004), esta Constitución modificó: 1) la organización del Ejecutivo; 2) la modalidad de relación entre los Poderes; 3) el procedimiento de integración de los entes autónomos y servicios descentralizados; 4) la forma de sancionar el presupuesto, y 5) el diseño orgánico de los gobiernos departamentales.

Con respecto al primer aspecto, se adoptó el colegiado integral: Consejo Nacional de Gobierno (CNG). Estaba integrado por nueve miembros: seis para el partido más votado ${ }^{6}$ y tres para el segundo partido más votado. ${ }^{7}$ La designación de los ministros recaía en el CNG por mayoría de votos, y los designados eran responsables ante el Parlamento.

En cuanto al segundo aspecto, se modificaron las normas para la censura de los ministros. Estos mantenían su responsabilidad política, pero se quitaba la posibilidad de que, en el marco de un conflicto entre los poderes, el Ejecutivo cayera por iniciativa del Parlamento o que el Ejecutivo disolviera a este último. «A diferencia de los dos textos anteriores, la Constitución de 1952 no preveía una solución institucional para esta clase de problemas» (Chasquetti, 2004, p. 77). Se mantuvieron los siguientes institutos parlamentarios: llamado a sala de los ministros, pedido de informes y censura de los ministros.

En lo que atañe al tercer aspecto, se estableció lo que popularmente se conoció como el 3 y 2: el CNG designaba los directorios de los entes autónomos y servicios des-

6 La lista más votada recibía los seis cargos. Si la segunda lista del lema ganador superaba un sexto de los votos del lema, la distribución cambiaba: cinco cargos para la lista más votada y uno para la segunda. La presidencia del CNG rotaba anualmente entre los integrantes de la mayoría. 
centralizados, con tres cargos a pluralidad de votos para la mayoría y dos para la minoría mayor. ${ }^{8}$ Una vez conformadas, las listas de los directorios eran enviadas por el Ejecutivo al Senado para ser consideradas; la Cámara podía observar o dejar sin efecto las designaciones por una mayoría de tres quintos de sus miembros.

En referencia al cuarto aspecto, se modificó el sistema presupuestal instalado a partir de 1934, de carácter anual. El presupuesto se elaboraría para la totalidad del período de gobierno y se realizarían sucesivas rendiciones de cuentas.

Con respecto al quinto aspecto, la composición orgánica de los ejecutivos departamentales se modificó siguiendo el formato del CNG. Estos órganos se llamaron concejos departamentales (CD).

Si observamos las modificaciones en el Poder Legislativo, la más notoria es la sustitución del presidente del Senado por el vicepresidente de la República, hecho que se da por el cambio de diseño orgánico del Ejecutivo. La Cámara de Diputados continuó teniendo 99 miembros electos por representación proporcional a partir de los votos de cada lema, con un mínimo constitucional de dos diputados por departamento (artículo 88). El Senado estaba integrado por 31 miembros elegidos por representación proporcional integral en circunscripción única nacional (artículos 94 y 95).

Para comprender el tipo de régimen de gobierno resultante de la Constitución de 1952, debe tenerse presente que un régimen presidencialista puro tiene: elección popular del Poder Ejecutivo colegiado, ${ }^{9}$ un gabinete que solo es responsable frente al presidente, mandatos fijos para el Legislativo y el Ejecutivo, y poderes de veto para el presidente sobre la producción legislativa del Parlamento (Shugart y Carey, 1992). En el caso abordado, los criterios 1, 3 y 4 se cumplen plenamente, mientras que con relación al 2 el cumplimiento es parcial (Chasquetti, 2004, pp.83-84). En síntesis, el presidencialismo uruguayo, con un Poder Ejecutivo colegiado, presentaba una de sus configuraciones más puras del siglo XX.

\section{Partidos y sistema electoral: las instituciones y los actores}

Como ha señalado Daniel Buquet (2004), la democracia uruguaya requirió una compleja obra de ingeniería electoral que articulara las características y los intereses de los partidos fundacionales. Además debe tenerse presente que los agentes políticos de relevancia son los partidos y sus fracciones, lo que hace importante observar tanto la

8 En el caso de directorios de siete miembros, cuatro cargos correspondían a la mayoría y tres a la minoría.

9 Un análisis comparado de los diferentes formatos del Poder Ejecutivo puede consultarse en Chasquetti (2018). 
fragmentación del sistema de partidos como la fraccionalización de los partidos. La clave explicativa de tal situación son los efectos que el sistema electoral produce sobre el sistema de partidos, en el marco de un régimen de gobierno presidencialista.

Los elementos básicos del sistema electoral vigente en el momento histórico abordado se gestaron entre 1910 y 1942. Las características definitorias del sistema electoral eran: mayoría simple (MS) para la elección presidencial; representación proporcional (RP) en el Parlamento; múltiple voto simultáneo, y elecciones simultáneas vinculadas a nivel de lemas con listas cerradas y bloqueadas (Chasquetti y Moraes, 2000, p. 310). La MS para la elección presidencial desestimulaba la aparición de nuevos partidos y ejerció una presión hacia un tendiente bipartidismo. Al mismo tiempo, el doble voto simultáneo (DVS) y la RP permitían a las fracciones coexistir dentro de los partidos tradicionales y competir por la hegemonía interna o tan solo por permanecer de manera testimonial o buscar, según fuera su peso electoral, ciertos niveles de participación u otros pagos. La RP a nivel parlamentario actúa como estímulo para la proliferación de agentes electorales, pero la vinculación y la simultaneidad de elecciones legislativas y presidenciales atenuó el estímulo de formar nuevos partidos. Por lo tanto, el surgimiento de múltiples agentes electorales se dio dentro de los partidos, donde se formaron fracciones que votaban dentro de un mismo lema y a la vez competían entre sí por las bancas del Parlamento, y esta forma de competencia se veía estimulada por el múltiple voto simultáneo. En resumen, mientras la RP estimuló la fragmentación, la MS para la elección presidencial la contuvo, orientando hacia una competencia bipolar por la Presidencia. Por otra parte, la combinación de reglas produjo efectos que llevaron a la configuración de partidos fraccionalizados pero tendientes a una bipolarización interna (Chasquetti y Moraes, 2000, p. 311). De esta manera, «[...] el sistema electoral uruguayo era funcional a un sistema bipartidista fraccionalizado» (Buquet, 2004, p. 170).

Siguiendo el análisis de Chasquetti y Moraes (2000, pp. 311-317), el sistema de partidos uruguayo muestra una estructura política con un alto nivel de institucionalización, baja volatilidad electoral y barreras para el surgimiento de nuevos partidos. Los partidos tradicionales poseen un formato fraccionalizado de agentes de gran visibilidad pública y con estructuras de liderazgo consolidadas. La ausencia de un jefe de partido y de órganos de decisión de conjunto con un efectivo control sobre toda la colectividad lleva a que los jefes de fracción controlen la competencia interna y elaboren las listas de sus fracciones, lo que les proporciona un elemento de premio y castigo a la actitud de los integrantes de su fracción. Así, un presidente electo solamente puede controlar las decisiones de su fracción y se da una coexistencia de intereses: por un lado los del partido y por otro los de las fracciones. Entonces el presidente y su fracción deben negociar con las fracciones - y los líderes - de su partido, y en caso de ser necesario para obtener las mayorías parlamentarias que no se puedan alcanzar con las bancas de su partido la negociación se amplía a fracciones de otros partidos. Los presidentes electos poseen 
un conjunto de recursos institucionales que les permiten negociarlos, cuando existe demanda, por apoyo parlamentario: cargos en el gabinete, en los entes autónomos, etcétera. Los procesos de negociación para lograr algún tipo de acuerdo de gobierno pueden llevar a la modificación de la agenda de gobierno que el presidente electo presentó durante la campaña. Como veremos más adelante, la formación del gobierno encabezado por Luis Batlle tuvo las características antes señaladas.

\section{La dinámica política}

Los resultados de las elecciones de 1954 muestran a la Lista 15 controlando el Ejecutivo, y al PC ostentando mayoría parlamentaria. Pero el formato de los partidos que ya hemos señalado nos arroja otra realidad: el presidente —en este caso del $\mathrm{CNG}^{10}$ - deberá negociar para obtener apoyos para gobernar. Los incentivos para la formación de coaliciones, o acuerdos intrapartidarios entre fracciones, están determinados por la falta de apoyo parlamentario para aprobar políticas. El formato institucional y el tipo de partido político que se presenta en el sistema son claves para entender el proceso.

Como plantean Daniel Chasquetti y Juan Andrés Moraes (2000, pp. 320-321), en un régimen de gobierno como el uruguayo la maximización de beneficios y la minimización de costos por parte de los agentes políticos se sustenta en que, ante una buena gestión del presidente, los beneficios son para su partido o su fracción y no para las fracciones o partidos cooperantes. Sin importar cómo sea la gestión del gobierno, la defección es segura, ya que al acercarse la elección, o al agotarse la agenda negociada, quienes cooperaron tienen incentivos para retirarse y competir electoralmente.

Si atendemos al modelo de partido de este caso analizado, encontramos que quien ocupa el Ejecutivo puede ser jefe de fracción, pero no siempre lo es de partido, y esto implica que no sea fácil para él el controlar la disciplina parlamentaria de la totalidad de su partido. De esta manera, partidos y fracciones actúan con un ciclo pautado por la cooperación al comienzo y la tendencia posterior a la competencia y el conflicto. La existencia de elecciones prefijadas determina que la actitud cooperativa no dure todo el mandato, sino que disminuya a medida que la elección se acerca. Como veremos, Batlle Berres debió hacer concesiones para obtener el apoyo parlamentario necesario, negociando cargos por apoyo político (Strom, 1990).

De aquí en más, cuando el texto se refiere al presidente después de la reforma de 1952, hace referencia al presidente del Consejo Nacional de Gobierno, dado el formato colegiado del Poder Ejecutivo que plantea la Constitución de la época. 


\section{Los partidos, la campaña electoral y los resultados electorales}

La relación conflictiva entre la 14 y la 15 se remonta a la elección de 1946, con la primera perfilada hacia el conservadurismo. ${ }^{11}$ Luis Batlle tuvo el desafío de instituir un discurso auténticamente batllista sin contar con El Día y enfrentándose a los hijos de Batlle y Ordóñez. Desde el diario vespertino Acción y desde los micrófonos de Radio Ariel, Batlle Berres buscó construir una imagen de continuador genuino del batllismo de don Pepe.

Para los comicios de 1954, la 14 realizó una alianza con Libertad y Justicia, sector liderado por Eduardo Blanco Acevedo al que ya se habían integrado en 1946 los riveristas; con ello se configuró una nueva ala conservadora unificada dentro del PC. Se repetía la competencia interna bipolar dentro del partido, ya no como batllistas y antibatllistas, sino que bajo la denominación de batllismo convivían tanto conservadores como progresistas (Buquet 2004, p. 153). El coloradismo independiente, ya en franca decadencia, se presentó a las elecciones encabezado por un viejo baluarte del terrismo: César Charlone.

La separación entre la 14 y la 15 se acentuó. Batlle Berres, a pesar de que los ministros y representantes de su sector aprobaron las medidas del gobierno, fustigó con dureza el conservadurismo de la 14. La búsqueda de Luis Batlle por mostrarse diferente al gobierno y además presentarse como un actor proclive al diálogo lo llevó a criticar la aplicación de las medidas prontas de seguridad por parte del primer CNG. Los impactos económicos de la coyuntura internacional sobre el precio de la lana y su consiguiente efecto sobre la industria textil se hacían sentir, en el marco de un proceso inflacionario. Como señala Chagas:

1952-1954 no fue un período fácil. El gobierno tuvo que implantar Medidas Prontas de Seguridad para enfrentar los conflictos sindicales en Salud Pública y en el transporte montevideano. Luis Batlle mantuvo - en un principio- una prudente distancia de este gobierno, sin atacarlo frontalmente pero tampoco sin realizar una defensa entusiasta. Sin embargo, a medida que se acercaban las elecciones Luis Batlle se mostró más crítico del gobierno. (2018, pp. 39-40)

Dado que el tema es presentado rápidamente en el texto y no se atiende en profundidad, es necesario hacer una advertencia relevante. Existen trabajos que muestran los orígenes de estas diferencias e historizan las tensiones entre ambas fracciones, mostrando su complejidad, formulando nuevas preguntas y repensando los tiempos históricos en los que este proceso de ruptura y sus diferentes dimensiones tuvieron lugar. Entre ellos cabe destacar el de Chagas (2018) y el de Ferreira (2013b). 
En ese contexto, desde Acción Batlle Berres manifestó: «Medidas de seguridad no. Libre y amplia discusión con los obreros, sí. He ahí la diferencia en lo social entre ellos y nosotros» (Rompani, 1965, p. 139). Este planteo tuvo gran receptividad en el movimiento sindical y a esto Luis Batlle sumó otros pronunciamientos políticos para presentarse como oposición al gobierno y en especial a la otra fracción del batllismo. Se negó, durante la campaña electoral, a todo posible acuerdo de candidaturas comunes en una sola lista y «[...] afirmó la necesidad de un gobierno homogéneo, en el que todos sus integrantes actuasen con identidad de ideas y propósitos, lo cual sintetizó en su afirmación: «Todo o nada» (D’Elía 1982, p. 66). En un juego discursivo comparó los avances de su período con el repliegue conservador del primer colegiado. El líder quincista insistió en su propuesta de «renovación y reforma». Formó la lista a los cargos legislativos con un grupo de jóvenes políticos, a quienes presentó como una alternativa de renovación ideológica y prácticas políticas. ${ }^{12}$ El apoyo popular se volcó en los comicios hacia el PC y, dentro de este, hacia la 15.

La 15 proponía una vuelta a los lineamientos de gobierno de la anterior presidencia de su líder. La agenda de gobierno que se puede extraer de los discursos de campaña muestra un énfasis en la continuación de la implantación de una sociedad industrial, en la cual el Estado jugaría un papel dirigista y planificador, donde la función estatal arbitral y conciliadora sería la pieza fundamental del mantenimiento de una armonía de clases que le permitiese al luisismo ${ }^{13}$ mantener el apoyo de una base social policlasista crecientemente urbana. La apuesta para superar la crisis se apoyaría en el fomento de la industria basada en materias primas nacionales —en especial el sector textil-y la apertura de mercados exteriores, en particular Estados Unidos. Esta orientación implicaba el mantenimiento del dirigismo cambiario, aspecto que perjudicaba al sector ganadero, el cual reaccionó y presionó al gobierno. Los industriales, en el marco de una creciente caída de sus ganancias, también se enfrentarían al segundo colegiado debido a la tendencia obrerista esbozada. Estos hechos serían aprovechados por la oposición.

La contienda electoral no solamente mostró la oposición de los colorados no quincistas, sino también la del nacionalismo. En tiendas del PN, Herrera siguió siendo la figura opositora más visible, aunque comenzaron a verse elementos que cuestionaban su hegemonía partidaria. Esta elección, que sería la última que presentara por un lado al PN y por otro al PNI, comenzó a ambientar los cambios que vendrían. Mientras tanto, la Liga Federal de Acción Ruralista, liderada por Benito Nardone, continuaba creciendo.

Un estudio que arroja luz sobre este proceso es el de Ferreira y Rodríguez (2017), donde este tema se aborda a partir del análisis de la carrera política de Zelmar Michelini en esta fracción. Los autores plantean cuánto de este proceso pudo motivarse por la «emigración» de dirigentes tradicionales hacia el liderazgo de Martínez Trueba. como Lista 15, o la 15, liderada por Batlle Berres (Ruiz, 2007, p. 128). 
Cuadro 1. Resultados de las elecciones de 1954

\begin{tabular}{|c|c|c|c|c|c|c|}
\hline & \multicolumn{3}{|c|}{ Votos } & \multicolumn{3}{|c|}{ Bancas del Senado } \\
\hline & \multirow[t]{2}{*}{ Absolutos } & \multicolumn{2}{|c|}{$\%$} & \multirow[t]{2}{*}{ Absolut } & \multicolumn{2}{|c|}{$\%$} \\
\hline & & S/partido & S/total & & S/partido & S/total \\
\hline Lista 15 & 254.639 & $57,30 \%$ & $28,96 \%$ & 10 & $58,82 \%$ & $32,26 \%$ \\
\hline Lista 14 & 143.54 & $32,30 \%$ & $16,33 \%$ & 6 & $35,29 \%$ & $19,35 \%$ \\
\hline Al sublema & 120 & $0,03 \%$ & $0,01 \%$ & & & \\
\hline $\begin{array}{l}\text { Sublema Batllismo - Libertad } \\
\text { y Justicia }\end{array}$ & 36.611 & $8,24 \%$ & $4,16 \%$ & 1 & $5,88 \%$ & $3,23 \%$ \\
\hline Lista 65 (Independientes) & 9.292 & $2,09 \%$ & $1,06 \%$ & & & \\
\hline Al lema & 227 & $0,05 \%$ & $0,03 \%$ & & & \\
\hline Total Partido Colorado & 444.429 & $50,55 \%$ & & 17 & & $54,84 \%$ \\
\hline Con Herrera por la Soberanía & 160.743 & $51,88 \%$ & $18,28 \%$ & 6 & $54,55 \%$ & $19,35 \%$ \\
\hline $\begin{array}{l}\text { Movimiento Popular } \\
\text { Nacionalista }\end{array}$ & 112.128 & $36,19 \%$ & $12,75 \%$ & 4 & & $12,90 \%$ \\
\hline Reconstrucción Blanca & 36.818 & $11,88 \%$ & $4,19 \%$ & 1 & & $3,23 \%$ \\
\hline Al lema & 129 & $0,04 \%$ & $0,01 \%$ & & & \\
\hline Total Partido Nacional & 309.818 & & $35,24 \%$ & 11 & & $35,48 \%$ \\
\hline $\begin{array}{l}\text { Partido Nacional } \\
\text { Independiente }\end{array}$ & 32.341 & & $3,68 \%$ & 1 & & $3,23 \%$ \\
\hline Unión Cívica & 44.255 & & $5,03 \%$ & 1 & & $3,23 \%$ \\
\hline Partido Socialista & 28.704 & & $3,26 \%$ & 1 & & $3,23 \%$ \\
\hline Partido Comunista & 19.541 & & $2,22 \%$ & & & \\
\hline F. Anticolegialista P. & 89 & & $0,01 \%$ & & & \\
\hline Partido Obrero & 65 & & $0,01 \%$ & & & \\
\hline TotAlES & 879.242 & & $100 \%$ & 31 & & $100 \%$ \\
\hline
\end{tabular}

Fuente: Buquet, Chasquetti y Moraes, 1999 
La fragmentación del sistema de partidos medida a través del número efectivo de partidos (NEP) con representación en el Senado ${ }^{14}$ arroja un índice de 2,24. Esto muestra un nivel moderado de fragmentación, lo que lleva a Buquet a calificar al sistema de partidos de la época como un bipartidismo plus (Buquet et al., 1999, p. 39). Si se mide de la misma forma la fraccionalización de los partidos, el PC presentaba un número efectivo de fracciones igual a 2,11 y el PN a 2,66. ${ }^{15}$

El PC logró la mayoría parlamentaria, lo que permitía suponer que podría llevar adelante un gobierno de partido mayoritario. Pero si observamos más detenidamente, atendiendo a la composición de las bancadas por fracción, podemos ver que Luis Batlle no poseía la mayoría para gobernar solamente con la bancada de su fracción, ya que solo controlaba un grupo de 10 senadores y 33 diputados.

Como ha señalado Sacchi (1999) al estudiar los gobiernos bajo la Constitución de 1952, como punto de sustento de estas administraciones pueden considerarse las relaciones intrapartidarias, donde la bancada de la fracción mayoritaria es el referente básico del Ejecutivo en el Parlamento, mientras que las fracciones menores del partido son las buscadas para obtener las mayorías parlamentarias necesarias.

Vistos los resultados y el mapa político configurado en el Senado, se presenta a continuación el proceso de formación del gobierno.

\section{La formación del gobierno}

La formación del gobierno comenzó a negociarse desde que se conocieron los resultados electorales hasta casi la asunción, el 1. ${ }^{\circ}$ de marzo de 1955, de los integrantes del CNG. ${ }^{16}$ Si observamos los datos globales, el PC estaba en condiciones de establecer un gobierno de partido constituyendo un gabinete monocolor, ya que poseía 17 bancas senatoriales y también mayoría de diputados. Pero si recordamos las características del sistema de partidos, se hace necesario observar el peso de las fracciones en la interna del PC. El contingente legislativo del presidente electo corresponde, en primer término,

Siguiendo a Buquet (2000), se toma el Senado como ámbito óptimo para medir la fragmentación y la fraccionalización partidarias, por ser un órgano cuya estructura se configura a nivel nacional. El NEP es un índice que representa el número de partidos hipotéticos de tamaño igual que tendrían el mismo efecto sobre la fragmentación del sistema de partidos que el que tienen los partidos reales de diverso tamaño.

El número efectivo de fracciones a nivel de listas al Senado que obtuvieron representación en ese ámbito reúne en el caso del PN las cifras del PNI.

Integrado por Luis Batlle Berres, Alberto Zubiría, Arturo Lezama, Carlos Fischer, Justino Zavala Muniz y Zoilo Chelle por la mayoría quincista, y, dentro del PN, Luis Alberto de Herrera y Ramón Viña por el herrerismo y Daniel Fernández Crespo por el Movimiento Popular Nacionalista. 
a las bancas que posee su fracción: 10, que se traducen en el 58,82\% del total de la representación de su partido en el Senado y el 32,26\% del total de dicha cámara. Las cifras muestran que la fracción del presidente por sí misma no tenía mayoría parlamentaria. Esto es condicionante, ya que el presidente debió negociar con la 14 para obtener el apoyo parlamentario necesario.

La negociación se realizó dentro del partido, con las fracciones como los actores relevantes. El resultado fue la formación de un gabinete monocolor y la constitución, al comienzo del mandato, de un gobierno de partido mayoritario. La negociación finalizó luego de que la 15 acordara con la 14 la nominación de titulares para cinco ministerios, ${ }^{17}$ la presidencia y nueve cargos de importancia en cinco entes. Este proceso friccionado entre dos fracciones que habían competido entre sí y se presentaban cada vez más distanciadas y polarizadas dentro del espectro político colorado no era un preámbulo que permitiese ver a un PC unificado, capaz de afrontar coherentemente la hechura de políticas públicas en el marco de una crisis que día a día se agravaba. Esta ríspida negociación no fue una excepción en los tiempos de los colegiados, como puede verse, por ejemplo, en la formación de los posteriores gobiernos del PN.

La negociación fue interconectada (Raifa, 1991) al contar con varios temas y dos actores centrales, la 15 y la 14, en dicho proceso. La polarización entre ambas fracciones era, al menos discursivamente, significativa. La 15 atacó duramente el conservadurismo de la 14, y esta última, además de considerar radical a la 15, fustigó con agudas críticas las tendencias que consideraba populistas y demagógicas del líder quincista.

Si se observa la arena parlamentaria, la realidad parece otra. A pesar de darse duros debates entre los integrantes de ambas fracciones, a la hora de las votaciones la 14 y la 15 apoyaron conjuntamente las iniciativas principales del primer colegiado, salvo al acercarse la elección de 1954. En cuanto actores, veremos que la 15 se presentó como un actor racional unificado - con la figura de Luis Batlle como conductor del sector-, mientras que la 14 se presentó como representante de lo que Graham Allison (1988) denominó modelo de política gubernamental, en el que los líderes que ocupan la cúspide de las organizaciones no constituyen un grupo homogéneo y cada integrante de este grupo es visto como participante de un juego político competitivo. Se ve aquí, por lo tanto, la configuración de negociaciones y pactos a través de circuitos regulados, y la acción puede entenderse como resultado de estos juegos de pactos.

Los actores contaron con diferentes recursos para la negociación. La 15, luego de buscar votos, obtenerlos y hacerse con el gobierno, poseía un conjunto de recursos institucionales - cargos - que le permitían negociar el apoyo parlamentario que buscaba. Por otra parte la 14, con un contingente de seis senadores, estaba en condiciones de 
proporcionar la mayoría parlamentaria que la 15 necesitaba. A cambio de ello, la 14 negoció en procura de cargos, lo que le permitía no solo impulsar políticas, sino también continuar, como lo hizo la 15, desplegando el uso del clientelismo como forma de aumentar y mantener sus redes de agentes políticos y votantes. En resumen, mientras la 15 buscó la mayoría parlamentaria para impulsar políticas públicas, la 14 en ese proceso buscó el acceso a cargos. ${ }^{18}$ Como bien señalan Gerardo Caetano y José Rilla: «El acuerdo avanzaba desde "adentro hacia afuera", intentaba ante todo acordar dentro del lema, incluso desde afinidades y parentescos [...]» (2000, p. 233). Aseguradas las mayorías legislativas dentro del lema, la dependencia o la demanda de recursos controlados por el PN, y por lo tanto los estímulos para conformar una coalición de gobierno, eran menores o casi inexistentes. Sí se ve la búsqueda de constituir mayoría parlamentaria con el sector minoritario del PC, asegurándole la aprobación de iniciativas legislativas mientras el acuerdo estuviera vigente. Y cuanto más depende un partido - o, en este caso, una fracción- de sus potenciales aliados, más concesiones estará dispuesto a hacer.

El relevamiento de prensa para observar el proceso de formación de gobierno mostró la interna colorada como el punto de atención de la prensa afín al nacionalismo. El diario El País señalaba sobre este asunto:

Entre otras consideraciones a las que se prestan los resultados de los comicios del domingo, hay una indiscutible que subrayamos: Las fracciones menores del Partido Colorado han desaparecido casi totalmente. Las divisiones y subdivisiones en los hechos ya no cuentan. Solo hay dos fuerzas: la del grupo de la $14 \mathrm{y}$ el bando de la 15. Puede decirse con propiedad que el Partido Colorado, hoy, es el batllismo. ${ }^{19}$

Los rumores sobre las posibles alianzas de la $15 \mathrm{y}$ los posibles miembros del gabinete no se hicieron esperar. El 2 de diciembre El País, en su sección «Lo que se dice», hizo públicos los primeros rumores sobre quiénes serían los futuros ministros. Se manejaban los nombres de Francisco Forteza como canciller, Armando Barbieri en Obras Públicas, Armando Malet en Hacienda y el general Fajardo en Interior. El mismo diario, en la sección mencionada, comenzó a manejar la noticia de un acercamiento y conversaciones oficiosas entre la 15 y la 14 el 5 de diciembre, al día siguiente del fallecimiento de Lorenzo Batlle. En esa ocasión se señaló el envío de una nota de felicitación de Eccher y Lanza, de la Agrupación Joaquín Suárez de la 14, a Luis Batlle, la que fue contestada u otra. Estas características son consustanciales al PC y el PN de la época, como lo advierte, por ejemplo, Solari (1962). 
cordialmente. Al final de la nota de respuesta, Luis Batlle decía: «Esperamos que las recíprocas obligaciones que tenemos todos, nos han de indicar los caminos que, atendiendo a los problemas que vive el país, nos permitan luchar por un Partido Colorado cada vez más fuerte y más pujante». ${ }^{20}$

También ese día se publicó en la página de los editoriales un análisis sobre las necesidades de la 15 de conseguir un respaldo parlamentario mayoritario, el que concluía que la mejor alianza posible era con la 14. La nota de Eccher y Lanza se manejó como indicio de este posible acuerdo. Sobre los cargos ministeriales, se señaló que los «más seguros», según rumores internos de la 15, eran Malet en Hacienda, Vasconcellos en Ganadería, Fajardo en Interior y Barbieri en Obras Públicas. ${ }^{21}$ También se señaló el ofrecimiento a Forteza de ocupar la Cancillería, ante el cual el candidato habría preferido presidir la Asamblea General o el Banco República. Sobre las posibles fórmulas de acuerdo con la 14 se dijo: «[...] se habla de que una de las fórmulas de acercamiento con la 14, sería Barbieri en Obras Públicas. [...] Giordano Eccher, en Relaciones, podría ser otro eslabón del acuerdo con la 14, de lo contrario, Rodríguez Fabregat y Abelardo Saenz, son los señalados como candidatos».22 También se manifestó que Rompani podría ser el futuro secretario del CNG y que se estaba pensando en Fariña para ocupar alguna cartera.

Desde El Debate, los herreristas, firmes opositores, manejaban rumores sobre los posibles acuerdos de la 15 y manifestaban su postura frente al futuro gobierno: «El Partido Nacional tiene el contralor y la misión de fiscal de la opinión pública frente al oficialismo». ${ }^{23}$

Mientras tanto, en tiendas coloradas, ni El Día ni Acción emitían comentarios sobre la negociación o los futuros posibles acuerdos. Sobre esta situación opinaba El País que, luego de la «agresiva» lucha, la 14 y la 15 «[...] han entrado en una suspensión de hostilidades que posiblemente desembocará en una paz donde ambos grupos volverán a disfrutar del gobierno, sin perjuicio de que al aproximarse las futuras elecciones vuelvan a repetir sus peleas $[. .]. » .^{24}$

El 18 de diciembre se hizo público, a través de El País, que los consejeros de la mayoría batllista se reunirían en Rocha para conversar sobre los planes de gobierno, y se puede pensar que también hablaron sobre la estrategia de negociación y los posibles futuros acuerdos para la formación de gobierno. El mes de enero fue cubierto por un

20 El País (7 de diciembre, 1954, p. 5).

21 Este cargo habría sido ofrecido por Luis Batlle a Barbieri mientras este se desempeñaba como intendente de Salto.

22 El País (5 de diciembre, 1954, pp. 2, 5).

23 El Debate (11 de diciembre, 1954, p. 5).

24 El País (14 de diciembre, 1954). 
manto de silencio; los colorados no hacían comentarios sobre el proceso. Los rumores plagaban El País, El Debate y Marcha.

En febrero fueron los colorados quienes dieron a conocer los detalles de la negociación y el acuerdo. El acercamiento a la 14 se fue haciendo con premura. El $10^{\circ}$ de febrero en la Casa del Partido Colorado, la 15 emitió una declaración sobre la vigencia y la legitimidad de la orgánica partidaria. En el punto III de dicha declaración los luisistas «[...] reafirman la confianza en soluciones políticas y gubernamentales que se basen en la unidad de nuestro Partido organizado e indiviso». ${ }^{25}$ En esa reunión, «En lo fundamental fue discutida la necesidad de fortificar la unión dentro de la 15 y hacerla dentro del Batllismo como manera de lograr esa gran unidad nacional [...]». ${ }^{26} \mathrm{Al}$ igual que la respuesta de Batlle Berres a Eccher y Lanza, esta era una muestra de la búsqueda de acuerdo entre ambas fracciones. Pero mientras la 15 se movía como un actor racional unificado, la 14 tenía dos sectores que tomaron posturas por momentos diferentes: el sector de El Día y la Agrupación Joaquín Suárez. Ambos buscaban cargos, pero el sector de El Día fue reticente a los acuerdos y hostigaba permanentemente al líder quincista.

El 2 de febrero, luego de la sesión preparatoria, se reunieron las bancadas de la 14 y la 15. El encuentro fue promovido por la 15 y en ella se acordó una reunión de todos los legisladores y miembros del CNG electos por ambas fracciones, que se fijó para el 7 de ese mes a la hora 21 en la Casa del Partido Colorado.

Al otro día de esa reunión, el editorial de Acción decía bajo el titular «La Nueva Agrupación de Gobierno»:

Anoche se reunió en la casa del Partido la nueva Agrupación de gobierno del Batllismo, que la constituyen 48 diputados y 16 senadores. Fue el primer triunfo del sector de la 15 en su empeño de darle vida y autoridad a los organismos del partido [...]. El orden del día estaba constituido por el tema de que, la Agrupación oficializara y radicara en ella las soluciones de unidad de gobierno que se vienen estudiando por delegados de la lista 15 y la Agrupación «Joaquín Suárez», conversaciones mantenidas hasta ayer por ciudadanos y desde anoche por delegados oficiales de la Agrupación de Gobierno que es, en definitiva, el órgano del Partido competente para el caso. [...] Es de esperar, igualmente, que el sector de la 14, pese y sienta la fuerza del mandato del Partido Colorado, que le ha dado al Batllismo 48 diputados y 16 senadores que habrían podido ser cincuenta si el sector de la «Joaquín Suárez» no hubiese dado sus votos en Cerro Largo y Rivera al núcleo minoritario del blancoacevedismo para vencer al Batllismo, pero no obstante esta actitud 
vivamente reprochable, lo cierto es que, Batllismo y Partido Colorado se confunden en una verdad transformada en una misma fuerza [...]..$^{27}$

El proceso de acercamiento entre las fracciones batllistas parecía marchar fructíferamente. El 9 de febrero Luis Batlle ofreció oficialmente a Gamarra el Ministerio del Interior. Al día siguiente, El Día comenzó con una dura crítica a la 15 sobre su actitud de buscar el apoyo de la 14. Esto complicaría la negociación y mostraría un recrudecimiento de las tensiones y el fin de la tregua entre las fracciones batllistas.

El Día acusó a la 15 de estar rectificándose del postulado «Todo o nada» por buscar el apoyo de la 14 y ofrecer a sus integrantes algunas carteras ministeriales. A esto respondía Acción:

El Día pretende sentar la tesis absurda de que nosotros, los que defendimos el «Todo o nada», estamos impedidos de ir a buscar o hacer mayorías parlamentarias, porque eso sería rectificarnos de nuestro eslogan de lucha. [...] El «Todo o nada» no ha tenido otra finalidad que darle unidad al Poder Ejecutivo [...] Los que constituimos la mayoría del Partido Colorado, y respaldados en la opinión pública, tenemos obligación frente a ella y somos una esperanza, reclamamos al sector minoritario de partido, respeten la voluntad de la mayoría y vengan con nosotros a formar unidad. [...] ya estamos poniendo a prueba la amplitud con que actuamos, cuando entregamos la cartera del Ministerio del Interior a un ciudadano de Derecho y servidor a lo largo de su vida, a la Justicia, como lo es el doctor Gamarra, y con ese mismo ánimo le ofrecemos algunas posiciones a los hombres de la $14 .^{28}$

Seguido a esto se convocaba a la unidad partidaria, diciendo que los colorados no podían ser la oposición de su propio partido, en referencia a El Día, que se planteaba la posibilidad de ser oposición por «principios» en determinadas situaciones. Frente a esta postura, Acción formulaba una irónica pregunta a la 14: «iSon colorados o forman otro partido?». En cuanto a la integración del gabinete con hombres de la 14, en esa oportunidad se citó el discurso de Luis Batlle en la noche del triunfo electoral:

No sabemos si [los hombres de la 14] cometerán el inmenso error de querer seguir la batalla y de esta manera crearnos dificultades en nuestro camino. No sabemos si lo harán. Por nuestra parte, hemos de ir a buscarlos para reclamarles que cumplan con la República y que cumplan con el Partido Colorado. No hemos cambiado absolutamente nada en nuestros planteos. Gobernaremos con nuestras mayorías 
legítimamente conquistadas desde el Poder Ejecutivo; pero necesitamos que los Ministros tengan respaldo parlamentario. ${ }^{29}$

El día 13, toda la prensa relevada publicó rumores de discrepancias internas en la 14 acerca de la postura que debían tomar ante un acuerdo con la 15. Por ejemplo, Cutinella y Fusco habrían manifestado que la fracción no debía integrar el gabinete pero sí los directorios de los entes, mientras otros sí querían ocupar ministerios.

El 15 comenzó la XXXVII legislatura. Acción tituló «El trabajo espera, la República reclama y el Partido exige». Al día siguiente estalló el conflicto con la 14. El senador catorcista Matto no habría respetado un acuerdo con la 15 y desde Acción se lo acusó de «traidor al partido». El acuerdo se hacía cada vez más difícil y el diario quincista decía:

En las tratativas de arreglo, la 15 ofreció al sector de la 14 dos ministerios: el de Relaciones Exteriores y el de Instrucción Pública, y cargos en los Entes Autónomos. Por imposición de la gente de El Día, se rechazó esta proposición, se reclamó cambiar el Ministerio de Relaciones Exteriores por el de Industrias, y así entendió que, salvando este obstáculo por nueva renuncia del sector de la 15, deseoso de alcanzar la unidad del Batllismo, el acuerdo se podría firmar [...].30

Moreno iría al Ministerio de Industria, pero el sector de El Día vetó la propuesta y se volvió a negociar por la Cancillería. Acción culpó a César Batlle de trabar la negociación:

Es necesario que se tenga bien en cuenta [decía el órgano de prensa quincista a la 14] que, si el acuerdo se hace, es bajo nuestras directivas y en la obligación de cumplirlo lealmente, sin trampas, sin el juego doble de entrar en el Gobierno y combatirlo, porque eso no lo podemos permitir y además, el Batllismo, no lo ha de querer aceptar y esto es no solo de buena política, sino de sana política. Nosotros somos triunfadores, los llamamos a participar del triunfo. Así actuamos [...], y torpes son los que nos crean débiles. Nosotros tenemos la responsabilidad de orientar, de otorgar posiciones, de elegir a los colaboradores, y además no hemos de permitir intromisiones en nuestras cosas y hemos de reclamar lealtad de todos a las soluciones que se alcancen». ${ }^{31}$

29 Acción (11 de febrero, 1955, p. 2).

$30 \quad$ Acción (16 de febrero, 1955, p. 3).

31 Acción (18 de febrero, 1955, p. 3). 
Las tensiones de la interna colorada parecían haber desembocado en la imposibilidad de llegar a un acuerdo. El 20 de febrero, bajo el titular «Primeros Obstáculos Al Gobierno Batllista», publicaba Acción los detalles de la fallida negociación con la 14, a modo de reclamo:

Anoche, después de muchos días de intensa labor, los dirigentes de la 14 dieron por terminadas las conversaciones que se venían realizando en el Batllismo, para llegar a una unidad de acción en el Gobierno, declarando que no aceptan Ministerios ni posiciones en los Entes Autónomos; y actuarían con libertad para colaborar o no en la acción legislativa. ${ }^{32}$

En ese mismo artículo se explicitan los pasos de la 15 en la negociación para obtener la mayoría parlamentaria: el ofrecimiento a Gamarra (no identificado aún como hombre de la 15 y reconocido por su labor personal) de ocupar el Ministerio del Interior; el ofrecimiento a la 14 de dos ministerios, cinco presidencias de entes autónomos y una representación de cargos en esos entes proporcional a la votación obtenida. Señaló Acción:

Los dirigentes de la 15 en el cumplimiento de su deber [...] han venido actuando con amplitud, pero se han estrellado contra el sector de El Día presidido por el señor Cesar Batlle, que ha puesto como precio de la colaboración no solo los cargos ofrecidos por la 15, sino el veto al nombre de Washington Fernández, como Ministro de Obras Públicas, intentando mantener esa odiosa política de la gente de $E l$ Día, distribuidora de favores y con el uso y abuso de una autoridad que el Partido ha desconocido y que tanto daño le ha hecho hasta ahora». ${ }^{33}$

Resulta interesante ver cómo se insiste en que la «mayoría de la 14» quiere el acuerdo mientras el sector de El Día no. A partir de ese momento Acción concentró la confrontación con el sector de El Día. El 21 de febrero, en Acción se transcribía, bajo el título «El País Juzgará», el acuerdo preelectoral entre la 14 y el blancoacevedismo. Luego de fuertes críticas que calificaban al acuerdo de excluyente, se recordó que, a pesar de ello, la 15 le había ofrecido a la 14 formar gobierno. Culminaba el artículo diciendo:

La catorce, orientada por la gente de El Día, se opuso al acuerdo y rechazó las posibilidades de colaboración porque intentó vetar uno de los candidatos que la 15

32 Primeros obstáculos al gobierno Batllista (20 de febrero, 1955). Acción, p. 3. 
estimó conveniente llevar a uno de los Ministerios. El veto —-desde luego- no fue aceptado. Dos actitudes, dos conductas que el país juzgará. ${ }^{34}$

Se anunció que el 25 de febrero Luis Batlle informaría, desde los micrófonos de Radio Ariel, sobre los esfuerzos de la 15 para lograr el apoyo del sector minoritario del batllismo. En ese ínterin, el 23 se reunió la Agrupación Joaquín Suárez para reconsiderar el acuerdo con la 15. Acción señaló en esa oportunidad que la decisión de no acordar era «forzada por una minoría» y que dentro de la 14 había descontento con el sector de $E l$ Día. Señalaba: «[...] la información es que esta noche serán derrotados los dirigentes de El Día [...] [Y] muy seguramente las soluciones de acuerdo se han de alcanzar con colaboración leal de la $14[\ldots] » .^{35}$

La reunión de la 14 acordó por mayoría la siguiente resolución transcripta en $A c$ ción: «La Agrupación "Joaquín Suárez" resuelve prestar su colaboración solicitada por el sector mayoritario del Partido, no obstante mantener su observación a la anunciada provisión del Ministerio de Obras Públicas». Desde filas quincistas se calificó de ambigua la declaración y se señaló que, si Fernández era fustigado por El Día y no recibía el apoyo necesario de la bancada catorcista, «[...] la observación entonces es la crisis ministerial desde el mismo instante que inicie su gestión». Se culpó a César Batlle por «[...] la demora y las dudas que se han creado respecto a la formación del Gobierno [...]», ${ }^{36} \mathrm{y}$ se anunció para esa misma noche una reunión de la 15 para resolver qué postura tomar frente a la declaración.

El día de asunción del nuevo gobierno se acercaba. El 25 de febrero la 15 hizo pública su resolución frente a la declaración de la Agrupación Joaquín Suárez:

La acepta, porque la declaración [....] no contiene reparos a la ética del candidato al Ministerio de Obras Públicas, implica la colaboración integral de la Agrupación Joaquín Suárez, comprometiéndose sus componentes a prestar su apoyo al Gabinete y a colaborar de igual manera con el Sector mayoritario en los Entes Autónomos y Servicios Descentralizados. En la mañana de hoy se reunieron los delegados de ambos sectores del Batllismo, que lo son los Consejeros Dr. Alberto Zubiría y Sres. Arturo Lezama y Carlos Fischer con los señores Dr. Luis A. Brause, Agr. Germán Barbato y Sr. Orestes Lanza que ejercen representación de la Agrupación Joaquín Suárez. Los delegados convinieron aceptar los términos de la declaración del Sector mayoritario del Partido [...]. Más tarde [...] se reunieron los miembros del Consejo electos por la mayoría, a los efectos de enterarse del resultado de la

El país juzgará. (21 de febrero, 1955, p. 3).

Acción (23 de febrero, 1955, p. 3).

Acción (24 de febrero, 1955, p. 3). 
reunión, quedando con el mismo finiquitadas las tratativas del acuerdo. Se propone que en el día de mañana el Consejo procederá a confirmar los ministerios en principio acordados. ${ }^{37}$

En estas reuniones quedó cerrado el acuerdo que se pudo observar cuando se nombraron los Ministros. El 26 de febrero, en la portada de Acción y bajo el titular «El Futuro Gabinete», aparecieron los ministros presentados con su foto y biografía en la cual se señalaba, en algunos casos, su procedencia política.

Cuadro 2. Integración del primer gabinete del gobierno iniciado en 1955

\begin{tabular}{|l|l|}
\hline Ministerio & Ministro \\
\hline Interior & Francisco Gamarra \\
\hline Relaciones Exteriores & Santiago Rompani \\
\hline Hacienda & Armando Malet \\
\hline Defensa & Gral. Juan Ribas \\
\hline Obras Públicas & Washington Fernández \\
\hline Salud Pública & Julio César Estrella \\
\hline Ganadería & Ramón F. Bado \\
\hline Industria y Trabajo & Carlos B. Moreno \\
\hline Instrucción Pública y Previsión Social & Renán Rodríguez \\
\hline
\end{tabular}

Fuente: Acción (1955).38

La composición del gabinete refleja la negociación. Cuatro de los nueve ministros eran connotados hombres del entorno de Luis Batlle: Rompani, Malet, Fernández y Estrella. De los ministerios negociados con la 14, uno fue para Gamarra, que no tenía militancia en filas del PC, pero recibió el consenso de la 15 ya que se lo veía afín a esta fracción. Lo mismo ocurrió con Bado, de orígenes terristas, pese a tener una relativa cercanía con la 15. También de origen terrista era el general Ribas, apoyado por la 14 y con un claro perfil conservador. Completaban la nómina Moreno y Renán Rodríguez, ambos de la 14. Como se ha señalado, la negociación también implicó la cesión a la 14 de cinco presidencias de directorios de entes y nueve cargos más en ellos. 
El lunes 28 de febrero el editorial de Acción señalaba: «El gabinete, efectuado en base a razones de orden político, deberá ser el fiel realizador del pensamiento del Ejecutivo, donde la 15 mantiene su mayoría para dar soluciones y hacer marchar el gobierno». ${ }^{39}$ Se formó un gabinete monocolor, que representó un gobierno de partido mayoritario hasta el 9 de mayo de 1956. El acuerdo entre la 15 y la 14, a nivel intrapartidario, puede verse como una coalición de fracciones estrictamente ganadora (Riker, 1962), que incluyó las necesarias para alcanzar una mayoría parlamentaria, de modo que las que acuerdan maximizan sus beneficios por no tener que compartirlos con socios que no aportan recursos estrictamente necesarios para obtener esa mayoría.

La formación del gabinete ministerial y la distribución de cargos en los entes se hicieron teniendo en cuenta la necesidad de la 15 de asegurarse una mayoría parlamentaria. Al comienzo del mandato se realizaron planteamientos que permitían pensar en un accionar en dirección a la superación de la crisis, de continuar el ritmo expansivo. Esto puede inferirse de dos discursos de Luis Batlle: el realizado al prestar juramento ante la Asamblea General -1. ${ }^{\circ}$ de marzo de 1955- y el difundido por cadena radial nacional el 18 de julio del mismo año. En ambos se muestra la orientación del gobierno hacia el industrialismo, la defensa de la producción nacional, la búsqueda de mercados exteriores y la conciliación de los conflictos de clase. Es interesante señalar que, en el segundo de los discursos mencionados, Luis Batlle denunciaba la falta de colaboración de la 14. La coyuntura de la crisis continuaba su profundización.

[El gobierno y la oposición] tuvieron plena conciencia de la profundidad de la crisis con la inevitable desocupación, aumento de precios, especulación y desabastecimiento, lo que originó inseguridad y descontento crecientes. Para la oposición, la coyuntura, manejada con habilidad, abría la perspectiva de capitalizar ese descontento y provocar cambios en la correlación de fuerzas políticas. (D’Elía 1982, p. 86)

La oposición política a la 15 fue dura y vehemente, tanto por parte de la 14 como desde filas de otros partidos. Las discrepancias entre la 14 y la 15 rápidamente se hicieron evidentes, lo que dificultó la tarea gubernativa para enfrentar la crisis. La conducta de los integrantes de la 14 fue el origen de sucesivas crisis ministeriales que desembocaron en la ruptura del acuerdo entre las dos fracciones batllistas, lo que llevó a la 15 a gobernar con minoría en el Parlamento, obligada negociar acuerdos puntuales. El 4 de agosto de 1955 presentaron renuncia los ministros catorcistas Renán Rodríguez - Industria y Trabajo- y Carlos B. Moreno - Instrucción Pública y Previsión Social一. Esto 
sucedía mientras los metalúrgicos emprendían una dura huelga, contexto en el cual María del Carmen Díaz fue asesinada por «los rompehuelgas», según los órganos de prensa sindicales y de los partidos Comunista y Socialista. La crisis ministerial terminó cuando a los pocos días, luego del diálogo entre fracciones, los ministros se reintegraron a sus cargos. Esta situación anunciaba otras de mayor gravedad.

El año 1956 comenzó agitado. Mientras Luis Batlle abandonaba la presidencia del CNG, en Fray Bentos se iniciaba el conflicto sindical más grande de ese año (protagonizado por los trabajadores de la carne). El 9 de marzo, con motivo de una interpelación realizada por el senador catorcista Carlos Matto al ministro de Salud Pública, el quincista Dr. Julio C. Estrella, este presentó su renuncia. Frente a este hecho, inmediatamente renunciaron los ministros Renán Rodríguez y Carlos Moreno, y luego de ello todo el gabinete hizo lo mismo. Según Amílcar Vasconcellos, la conducta de Matto desencadenó la ruptura definitiva del acuerdo político entre ambos sectores batllistas, lo que llevó a la 15 a tener que gobernar sin el debido respaldo parlamentario (Vasconcellos, 1959, p. 66).

El nuevo gabinete quedó integrado por Alberto Abdala en Interior, Francisco Gamarra en Relaciones Exteriores, Armando Malet en Hacienda, Florentino Guimaraes en Defensa, Washington Fernández en Obras Públicas, Vicente Basagoiti en Salud Pública, Amílcar Vasconcellos en Ganadería, Fermín Sorhueta en Industria y Trabajo, y Clemente Ruggia en Instrucción Pública y Previsión Social. Los cambios en el gabinete se dieron en la semana que comenzó con la crisis ministerial, el 9 de mayo de 1956, y el nombramiento de los ministros se completó el 16 de mayo. Del gabinete original se mantuvieron tres ministros: Malet, Gamarra y Fernández. Malet y Fernández mantuvieron la cartera original a la que habían sido designados cuando asumió el gobierno: Hacienda y Obras Públicas respectivamente. Gamarra culminó su proceso de acercamiento al círculo de confianza de Luis Batlle y pasó del Ministerio del Interior al de Relaciones Exteriores.

Los restantes ministros nombrados también procedían de filas de la 15. La serie de ministros de todo el restante período de gobierno muestra que, desde este momento hasta el final del mandato, todos fueron quincistas. La crisis ministerial del 9 de mayo de 1956 marca el comienzo de un gobierno minoritario de la 15 que se extendería hasta la asunción del PN, en 1959.

La 14 volvió a reposicionarse hacia la oposición y el bloqueo. Se puede ver en tal actitud la búsqueda de diferenciarse del gobierno y obtener de ello rédito político. $E l$ Día continuó siendo el portavoz de la fracción conservadora del batllismo, que adoptó una actitud crítica para con el gobierno, marcando sus discrepancias y planteando acusaciones. Luis Batlle llegó a señalar que era «[...] fácil en muchas ocasiones poner un artículo de El Día en las columnas del diario El Debate o un artículo de El Debate en las columnas del diario El Día» (Citado en D’Elía 1982, p. 92). Sobre la productividad parlamentaria del período señala D’Elía: 
[...] en el período comprendido entre abril de 1955 y enero de 1959, se promulgaron 414 leyes, entre las que no es posible encontrar una que encare a fondo los problemas fundamentales que enfrentaba el país. Aun la ley de presupuesto aparece limitada a un presupuesto de sueldos y recursos, con gastos mínimos que no contemplan inversiones reproductivas. Aproximadamente el 25\% de esas leyes está referido al otorgamiento de pensiones graciables y a homenajes que se rinden a personas, designando con sus nombres a instituciones oficiales. Hubo una abundante legislación laboral y social, pero fragmentaria, que significativamente fue aprobada en octubre de 1958, en vísperas de las elecciones. (1982, p. 87)

El Uruguay batllista en crisis daría paso a un ciclo de repliegue estatal y de liberalización amortiguada que se iniciaría con la victoria del PN, aliado al ruralismo, en las elecciones de 1958.

\section{Algunas consideraciones finales}

El análisis presentado a partir de la reconstrucción histórica muestra a la fracción del presidente como el núcleo del gobierno de 1955 y como a partir de ese núcleo se negoció con la segunda fracción con más bancas del mismo partido para formar el gobierno. En este sentido, la dinámica del caso analizado responde, en términos generales, a las características señaladas por Lanzaro (2000) y Sacchi (1999) sobre el período, y no se advierten prácticas de cogobierno (Caetano y Rilla, 1995, 2000). Sin embargo, a diferencia de lo planteado por Sacchi (1999) sobre la dinámica interpartidaria, se encontraron tensiones y conflictos significativos entre las dos fracciones coloradas claves en este proceso, la 14 y la 15.

El régimen de gobierno, el sistema electoral y el formato de los partidos pautaron una serie de incentivos para el desempeño político de los actores. El presidente Batlle Berres solamente controlaba a su fracción. Esto determinó que debiese negociar para lograr el apoyo de mayorías parlamentarias. Mientras la 15 buscó esto para poder aplicar políticas públicas, la 14 negoció por cargos el apoyo parlamentario.

El proceso de formación de gobierno mostró una negociación interconectada cuyo resultado fue un acuerdo interfraccional que permitió la formación de un gabinete monocolor en el marco de un gobierno de partido mayoritario, hasta 1956. Durante la negociación puede verse que Luis Batlle Berres deja por momentos un lugar importante a otros consejeros quincistas. Este aspecto muestra un interesante camino a explorar: las dinámicas del liderazgo que se dieron en el proceso.

Por otra parte, las dificultades para mantener la unidad partidaria y el acuerdo entre fracciones llevaron a que el gobierno tuviera problemas para responder frente a 
la crisis. Las relaciones entre el Poder Ejecutivo y el Legislativo mostraban indicios de haberse vuelto más complejas. Un ejemplo de ello es que las modificaciones introducidas en la política cambiaria, de gran importancia en ese momento, se realizaron mediante un decreto el 3 de agosto de 1956. La 15 culminó negociando ley por ley, debido a la ruptura del acuerdo con la 14. Queda aún por analizar la productividad parlamentaria del período para determinar cuáles fueron en este sentido el desempeño del gobierno y el nivel de bloqueo registrado, pero esto ya es campo para otra investigación.

\section{Bibliografía}

Allison, G. (1988). La esencia de la decisión. Buenos Aires: GEL.

Barrán, J. P., y Nahum, B. (1987). Batlle, los estancieros y el imperio británico: Volumen 8. La derrota del batllismo, 1916. Montevideo: Ediciones de la Banda Oriental.

Buquet, D. (2000). Fragmentación y fraccionalización política: De la oferta electoral a la conformación del gobierno. En J. Lanzaro (coord.), La «segunda» transición en el Uruguay. Gobierno y partidos en un tiempo de reformas (pp. 259-296). Montevideo: Fundación de Cultura Universitaria.

Buquet, D. (2004). Elecciones y sistema electoral. En B. Nahum (dir.), El Uruguay del siglo XX: La política (pp. 137-171). Montevideo: Ediciones de la Banda Oriental.

Buquet, D., Chasquetti, D., y Moraes, J.A. (1999). Fragmentación política y gobierno en Uruguay: ¿Un enfermo imaginario? Montevideo: Universidad de la República, Instituto de Ciencia Política.

Caetano, G., y Rilla, J. (1995). Relaciones interpartidarias y gobierno en el Uruguay: 1942-1973. Revista Uruguaya de Ciencia Política, 8, 15-34.

Caetano, G., y Rilla, J. (2000). El gobierno como cogobierno: Despliegues y repliegues de la partidocracia uruguaya, 1942-1973. En J. Lanzaro (coord.), La «segunda» transición en el Uruguay: Gobierno y partidos en un tiempo de reformas (197-258). Montevideo: Fundación de Cultura Universitaria.

Chagas, J. (2018). La tradición política como «arma» en la lucha interna del batllismo: El conflicto entre la 14 y 15 (1947-1958). (Tesis de maestría). Universidad de la República, Departamento de Ciencia Política, Montevideo.

Chasquetti, D. (2004). El proceso constitucional en el Uruguay del siglo XX. En B. Nahum (dir.), El Uruguay del siglo XX: La política (pp. 137-171). Montevideo: Ediciones de la Banda Oriental.

Chasquetti, D. (2018). Tres experimentos constitucionales: El complejo proceso de diseño del Poder Ejecutivo en el Uruguay. Revista Uruguaya de Ciencia Política, 27(1), 41-64. 
Chasquetti, D., y Buquet, D. (2004). La democracia en Uruguay: Una partidocracia de consenso. Política, 42, 221-247.

Chasquetti, D., y Moraes, J. A. (2000). Parlamento y gobierno en el Uruguay: Hacia una teoría del ciclo político. En J. Lanzaro (coord.), La «segunda» transición en el Uruguay: Gobierno y partidos en un tiempo de reformas (pp. 297-337). Montevideo: Fundación de Cultura Universitaria.

D’Elía, G. (1982). El Uruguay neo-batllista: 1946-1958. Montevideo: Ediciones de la Banda Oriental.

Espeche, X. (2016). La paradoja uruguaya: Intelectuales, latinoamericanismo y nación a mediados de siglo XX. Bernal: Universidad Nacional de Quilmes.

Ferreira, P. (2013a). Análisis en dos tiempos del viraje de «la quince». Crítica Contemporánea. Revista de Teoría Política, 3, 1-7.

Ferreira, P. (2013b). La república perdida: Democracia y ciudadanía en el discurso político de los batllistas de la lista quince: 1946-1972. (Tesis de maestría). Universidad de la República, Departamento de Ciencia Política, Montevideo.

Ferreira, P., y Rodríguez, M. (2017). El periplo de Zelmar Michelini en la Lista 15, 19461958 (pp. 139-167). En G. Caetano (coord.), Zelmar Michelini: Razones de una conducta. Acción y pensamiento. Montevideo: Planeta.

Lanzaro, J. (2000). El presidencialismo pluralista en la «segunda» transición (19851996). En J. Lanzaro (coord.), La «segunda» transición en el Uruguay: Gobierno y partidos en un tiempo de reformas (pp. 19-196). Montevideo: Fundación de Cultura Económica.

Pérez, R. (1988). Cuatro antagonismos sucesivos: La concreta instauración de la democracia uruguaya. Revista Uruguaya de Ciencia Política, 2, 41-60.

Raifa, H. (1991). El arte y la ciencia de la negociación. México: Fondo de Cultura Económica.

Riker, W. (1962). Teoría de juegos y de las coaliciones políticas. En A. Batlle (comp.), Diez textos básicos de ciencia política (pp.151-169). Ariel: Barcelona.

Rompani, S. (1965). Luis Batlle: Pensamiento y acción (discursos y artículos). Volumen 2. Montevideo: Alfa.

Ruiz, E. (2007). El Uruguay próspero y su crisis. 1946-1964. En A. Frega, D. Bonfanti, M. Broquetas, I. Cuadro, A. Islas, R. Porrini, ... E. Ruiz, Historia del Uruguay en el siglo XX: 1890-2005 (pp. 123-162). Montevideo: Ediciones de la Banda Oriental.

Sacchi, M. (1999). Partidos, fracciones y gobierno en el segundo colegiado (1952-1966). Revista Uruguaya de Ciencia Política, 11, 9-34.

Shugart, M., y Carey, J. (1992). Presidents and assemblies: Constitutional design and electoral dynamics. Nueva York: Cambridge University Press.

Solari, A. (1962). Réquiem para la izquierda. Gaceta de la Universidad, 6(22), 6-12. 
Strom, K. (1990). A behavioral theory of competitive political parties. American Journal of Political Science, 34(2), 565-598.

Vasconcellos, A. (1959). Un país que perdió el rumbo. Montevideo: Medina. 